\title{
Development of a peptide targeting dopamine transporter to improve ADHD- like deficits
}

Terence K. Y. Lai ${ }^{1,2}$, Ping Su' ${ }^{1}$, Hailong Zhang ${ }^{1}$ and Fang Liu' ${ }^{1,2,3,4^{*}}$

\begin{abstract}
Attention-deficit hyperactivity disorder (ADHD) is a neurocognitive disorder characterized by hyperactivity, inattention, working memory deficits and impulsivity. Its worldwide prevalence is estimated to be $3-5 \%$ in children and adolescents. The mainstay treatment for ADHD is stimulant medications (e.g. methylphenidate), which increase synaptic dopamine by directly blocking dopamine transporter (DAT). Although these pharmacological agents are effective, they are often associated with various side effects including risks for future substance use disorders in ADHD patients. Here, we investigated an interaction between DAT and dopamine D2 receptor (D2R) as a novel target to develop potential therapeutics for the treatment of ADHD by using an interfering peptide (TAT-DAT $T_{N T}$ ) to dissociate this protein complex. We found that TAT-DAT ${ }_{N T}$ promotes locomotor behavior in Sprague-Dawley rats. Furthermore, using in vivo microdialysis and high-performance liquid chromatography, we found that the disruption of D2R-DAT elevates extracellular dopamine level. More importantly, the interfering peptide, TAT-DAT ${ }_{\mathrm{NT}}$, attenuates hyperactivity and improves spontaneous alternation behavior in spontaneously hypertensive rats (SHR) ----- a common animal model of ADHD. This work presents a different means (i.e. other than direct blockade by a DAT inhibitor) to regulate the activity of DAT and dopaminergic neurotransmission, and a potential target site for future development of ADHD treatments.
\end{abstract}

\section{Introduction}

Attention-deficit hyperactivity disorder (ADHD), characterized by hyperactivity and inattention, affects between 3 and $5 \%$ in children and adolescents worldwide $[1,2]$. Although the exact etiology of ADHD remains elusive, dysregulation of the dopaminergic system is heavily implicated due to the actions of the current ADHD treatments [3]. These pharmacological agents are stimulants such as methylphenidate [4], and they enhance dopaminergic neurotransmission by directly blocking dopamine transporters (DAT) [5]. Although they are effective clinically, there are concerns about potential drug abuse and risks for future substance use disorders [6-8]. Radiolabelling studies revealed that both methylphenidate and cocaine share similar binding patterns within the dopaminergic system (e.g. nucleus accumbens, etc.),

\footnotetext{
* Correspondence: fang.liu@camh.ca

${ }^{1}$ Campbell Family Mental Health Research Institute, Centre for Addiction and Mental Health, Toronto, ON M5T 1R8, Canada

${ }^{2}$ Department of Physiology, University of Toronto, Toronto, ON, Canada

Full list of author information is available at the end of the article
}

which is implicated in euphoria and repeated substance use [9-11]. More importantly, chronic administration of these direct blockers leads to up-regulation of DAT expression [12, 13], which possibly underlie the increased risk for subsequent substance use disorders $[14,15]$. Therefore, an improved ADHD treatment may strengthen dopaminergic neurotransmission without directly blocking DAT.

Dopamine is the predominant catecholamine in mammalian brain and is involved in neurological functions such as locomotion, cognition, emotion and reward [15, 16]. One of the key players in regulating dopamine signaling is the dopamine transporter (DAT). DAT belongs to the SLC6 family of $\mathrm{Na}^{+} / \mathrm{Cl}^{-}$dependent transporters, and is composed of 12 transmembrane domains and intracellular $\mathrm{N}$ - and C-termini. With its localization on the presynaptic membrane of dopaminergic nerve terminals $[17,18]$, DAT utilizes the $\mathrm{Na}^{+}$gradient created by the plasma membrane $\mathrm{Na}^{+} / \mathrm{K}^{+}$ATPase as the driving force to transport synaptic dopamine across cellular

(C) The Author(s). 2018 Open Access This article is distributed under the terms of the Creative Commons Attribution 4.0 International License (http://creativecommons.org/licenses/by/4.0/), which permits unrestricted use, distribution, and 
membrane $[19,20]$. Such reuptake action of DAT also serves to terminate dopamine signaling. The reuptake activity of DAT is greatly dependent on its membrane expression level, which is constantly under dynamic regulation. Furthermore, DAT can also be regulated through direct protein-protein interactions with intracellular proteins such as $\alpha$-synuclein [21], synaptogyrin-3 [22], etc.

We previously identified a direct protein-protein interaction between DAT and dopamine D2 receptor (D2R) [23], and this interaction is mediated through the first 15 amino acids (i.e. $\mathrm{M}_{1}-\mathrm{V}_{15}$ ) of DAT $\mathrm{N}$-terminus and the third intracellular loop of D2R. Functionally, through this interaction, D2R recruits DAT to plasma membrane and therefore enhances the reuptake of dopamine. Based on the amino acid sequence $\left(\mathrm{M}_{1}-\mathrm{V}_{15}\right)$ of the interacting region in DAT, we developed a cell-permeable peptide (TAT-DAT ${ }_{\mathrm{NT}}$ ) to disrupt this interaction.

Here we showed that the disruption of D2R-DAT interaction by TAT-DAT $\mathrm{NT}_{\mathrm{NT}}$ peptide stimulates locomotor behavior in normal and dopamine-depleted Sprague-Dawley rats by increasing extracellular dopamine, suggesting the TAT-DAT $\mathrm{NT}_{\mathrm{NT}}$ peptide might also exert beneficial effects in the animal model of ADHD. In agreement with our hypothesis, the administration of TAT-DAT $_{\mathrm{NT}}$ also rescues the hyperactivity, and improves spontaneous alternation behavior of spontaneously hypertensive rats (SHR) in a Y-maze, a commonly used animal model of ADHD. In summary, this study provides evidence to support the D2R-DAT interaction as a potential novel drug target for ADHD treatments.

\section{Methods}

\section{Experimental animals}

Three strains of male rats were included in this study: Sprague-Dawley (SD) rats, Wistar Kyoto (WKY) rats, and Spontaneously Hypertensive (SHR) rats. 8-week-old SD rats, 3-week-old WKY rats and 3-week-old SHR rats were respectively purchased from Charles River Laboratories (Montreal, Quebec, Canada). SHR rats originated at the Kyoto School of Medicine in 1963, where Okamoto mated an outbred Wistar Kyoto male with marked elevation of blood pressure to a female with slightly elevated blood pressure [24]. Young SHR rats are preferably used as an ADHD animal model, because they will become hypertensive at the older age. Upon arrival, with free access to food and water, animals were housed in a vivarium maintained at $22-24{ }^{\circ} \mathrm{C}$ room temperatures and on a 12:12 light-dark cycle. They were also given one week to acclimatize to the vivarium. All behavioral procedures were approved by the Animal Care Committee at Centre for Addiction and Mental Health.

\section{Drug}

TAT-DAT $_{\text {NT }}$ (YGRKKRRQRRRMSKSKCSVGLMSSVV) was commercially obtained from GenScript USA Inc. (Piscataway, NJ, USA), whereas TAT (YGRKKRRQRRR) control peptide was synthesized by Biomatik (Cambridge, Ontario, Canada).

\section{Surgery}

Guide cannulae for intracranial injections (HRS Scientific, Canada) were accurately positioned to reach the designated coordinates (AP $-1.0 \mathrm{~mm}, \mathrm{LM}+1.4 \mathrm{~mm}$, DV $-3.6 \mathrm{~mm}$ from bregma), and then secured in place with dental cement. Animals subjected to in vivo microdialysis had another guide cannula (SciPro Scientific Products \& Equipment, Ontario, Canada) inserted into the following coordinates (AP $+2.2 \mathrm{~mm}, \mathrm{LM}+1.2 \mathrm{~mm}$, DV $-5.6 \mathrm{~mm}$ from bregma) to measure extracellular dopamine level in the core region of nucleus accumbens.

Peptide-induced locomotor activity in SD, WKY and SHR rats Animals were placed in open-field chambers for $30 \mathrm{~min}$ daily on two to three consecutive days, constituting their baseline locomotor activities. On the experiment day, animals received their peptide treatments (intracerebroventricular injection; i.c.v.). The i.c.v. administration was chosen to avoid potential bioavailability limitations. Thirty minutes after the peptide administration, animals were placed in open field chambers, and their locomotor activities were recorded for $30 \mathrm{~min}$ to an hour. For SD rats, animals received $40 \mathrm{nmol}$ of TAT or TAT-DAT $\mathrm{NT}_{\mathrm{NT}}$. For WKY and SHR rats, they were given a wash-out period of 3 days before they received a different dose (i.e. $0.4 \mathrm{nmol}$ and $4.0 \mathrm{nmol}$ ) of peptide treatments. All peptide treatments were delivered intracranially.

\section{Acute dopamine depletion model in SD rats}

This protocol was adapted and modified from McDougall et al. [25]. Animals from the AMPT group received two intra-peritoneal injections of AMPT $(25 \mathrm{mg} / \mathrm{kg}$ each), separated by 2 hours. Subsequently, animals were placed in open-field boxes to track their locomotor activities for $30 \mathrm{~min}$ to confirm the validity of the model.

To examine the effects of TAT-DAT $\mathrm{NT}_{\mathrm{NT}}$, animals were placed in open field boxes for $15 \mathrm{~min}$ after the induction of dopamine depletion. Animals were then given an intracranial injection of $40 \mathrm{nmol}$ TAT or TAT-DAT $\mathrm{NT}_{\mathrm{NT}}$, and were immediately returned to open-field chambers for a 60-min recording session.

\section{Y-maze test}

The Y-maze consisted of three arms made of black plastic (56 cm long, $12 \mathrm{~cm}$ wide and $25 \mathrm{~cm}$ high) extending from a central platform at an angle of $120^{\circ}$. Animals were administered with either TAT or TAT-DAT ${ }_{\mathrm{NT}}$ (at 
the dose of $0.4 \mathrm{nmol}$; i.c.v.) $30 \mathrm{~min}$ before the Y-maze test. Subsequently, animals were placed at the end of one arm and allowed to explore freely among the three arms of the Y-maze for 8 minutes. An "arm entry" was made when an animal crossed one-third of the arm length from the central platform. The sequence of arm entries was observed and recorded. A successful alternation was defined as three consecutive entries into three different arms (i.e. $\mathrm{A}, \mathrm{B}$ and $\mathrm{C}$ arms) such as $\mathrm{ABC}, \mathrm{ACB}$, $\mathrm{BAC}, \mathrm{BCA}, \mathrm{CAB}$, or CBA. The percentage of spontaneous alternation behavior was determined as following:

$$
\text { SAB } \%=\frac{\text { \#alternation } \times 100 \%}{\# \text { total arm entries-2 }}
$$

\section{In vivo microdialysis}

Animals were anesthetized with inhalant isoflurane, and a microdialysis probe (MAB 9.14.2; SciPro, Canada) was inserted into the nucleus accumbens core. Throughout the experiment, animals were maintained under anaesthesia, and artificial cerebrospinal fluid $\left(\mathrm{NaH}_{2} \mathrm{PO}_{4} \quad 2.0 \mathrm{mM}, \mathrm{MgCl}_{2} \quad 1.0 \mathrm{mM}, \mathrm{CaCl}_{2}\right.$ $1.2 \mathrm{mM}, \mathrm{KCl} 2.7 \mathrm{mM}$ and $\mathrm{NaCl} 145 \mathrm{mM}$ ) was constantly pumped through the microdialysis probe at a rate of $0.5 \mu \mathrm{L} / \mathrm{min}$. The dialysate samples were treated with $40 \mathrm{mM}$ perchloric acid (PCA) and $5 \mathrm{mM}$ EDTA before subjected to the high-performance liquid chromatography (HPLC). The baseline of each animal was determined based on four dialysate samples. After establishing the basal level of extracellular dopamine, peptide treatments were injected (i.c.v.) through the guide cannula, and five more dialysate samples were collected after the administration to evaluate the peptide effect on extracellular dopamine level. At the end of the experiment, brains were collected for cresyl violet staining to confirm cannula placement.

\section{High performance liquid chromatography (HPLC)}

The detection and quantification of dopamine was performed in a similar protocol as previously described [26]. Prior to dialysate analysis, a standard curve consisted of a series of known dopamine concentrations was established for every experiment. The dopamine assay was performed on UHPLC system (Thermo Scientific ${ }^{\mathrm{Tn}}$ Dionex $^{\text {Tw }}$ UltiMate $^{\mathrm{Tm}}$ 3000) equipped with ECD-3000RS (Electrochemical cell: 6011RS, Thermo Scientific). Samples were injected automatically and separated on an analytical column Acclaim RSLC PA2, $250 \times 2.1 \mathrm{~mm}$, $2.2 \mu \mathrm{m}$ (Thermo Scientific, 074814). For dopamine assay, the applied potential for analytical cell was set as + $220 \mathrm{mV}$. The UHPLC system was operated at $400 \mu \mathrm{L} /$ min for 10 mins at $30{ }^{\circ} \mathrm{C}$ using test mobile phase
(Thermo Scientific). The column temperature was set to $30{ }^{\circ} \mathrm{C}$. The concentration of dopamine was measured relative to standard solutions using Chromeleon 7.2 Chromatography Data System (Dionex, Thermo Scientific).

\section{Locomotor apparatus}

Open-field chambers (Med Associates Inc., St. Albans, VT, USA) were used to measure the locomotor activity of the experimental subjects. The dimensions of each open-field chamber were $43 \mathrm{~cm}$ long $\times 43 \mathrm{~cm}$ wide $\times$ $30 \mathrm{~cm}$ high. The walls of each open-field chamber were made of Plexiglas with a ventilated top-cover. There were six 16-beam infrared arrays mounted along the walls each chamber, allowing automated measurements of horizontal locomotor activity (Program Activity Monitor version 5.08; Med Associates Inc.) A custom-built system of 16 clear polycarbonate boxes $\left(45 \times 20 \times 25 \mathrm{~cm}^{3}\right)$ was also used in this study. The length of each box had an array of 11 externally mounted infrared photodetectors spaced $4 \mathrm{~cm}$ apart and $2 \mathrm{~cm}$ above the cage floor. Photobeam interruptions were recorded as ambulatory counts on the computer system.

\section{Co-immunoprecipitation and Western blot}

Co-immunoprecipitation and Western Blot analyses were performed as previously described [27]. Briefly, rat striatal tissues were homogenized in ice-cold lysis buffer (50 mM Tris, $150 \mathrm{mM} \mathrm{NaCl}, 2 \mathrm{mM}$ EDTA, 1\% NP-40, $0.5 \%$ sodium deoxycholate, $\mathrm{pH}=7.4$, with protease inhibitor (Sigma-Aldrich)), and rotated for $1 \mathrm{~h}$ at $4{ }^{\circ} \mathrm{C}$. After being centrifuged at 12,000 g for $10 \mathrm{~min}$, the total solubilized protein extract was yielded in the supernatant. $1000 \mu \mathrm{g}$ solubilized protein extracted from rat striatal tissue was incubated in the presence of anti-D2R antibody (Proteintech Group, rabbit, catalogue\# 550841-AP) or control IgG (Merck Millipore, rabbit, catalogue\# 12-370), together with protein A/G plus agarose (Santa Cruz Biotechnology) overnight at $4{ }^{\circ} \mathrm{C}$. Pellets were washed, boiled for $5 \mathrm{~min}$ in SDS sample buffer (Bio-Rad) + 2-Mercaptoethanol (a reducing agent; Sigma-Aldrich) and subjected to SDS-PAGE. 50 $100 \mu \mathrm{g}$ of protein extracted from tissue was used as a control in each experiment. After transfer of proteins onto nitrocellulose, membranes were Western blotted with the primary antibodies specified below. The intensity of protein level was quantified by densitometry (software: Image Lab, Bio-Rad). The antibodies used include anti-D2R (Santa Cruz Biotechnology, mouse, catalogue\# sc-5303) and anti-DAT (Santa Cruz Biotechnology, rat, catalogue\# sc-32258). More information, the D2R antibody from Santa Cruz Biotechnology was previously validated using $\mathrm{D} 2 \mathrm{KO}$ animals and the data have been published [27]. The other D2R antibody from Proteintech was validated 
by another research group using cell culture and siRNA against Drd2 [28].

\section{Data analysis}

Unless stated otherwise, behavioral data and co-immunoprecipitation data were analyzed by two-way ANOVA with/without repeated measures using IBM SPSS Statistics 21 (IBM Corporation). Co-immunoprecipitation data was analyzed by t-test, or one-way ANOVA followed by Bonferroni post-hoc test. All graphs presented in this paper were constructed by GraphPad Prism 5. All data were presented as Mean \pm SEM unless otherwise stated.

\section{Results}

The disruption of D2R-DAT stimulates locomotor activity

As aforementioned, we developed an interfering peptide (TAT-DAT ${ }_{\mathrm{NT}}$ ) to disrupt the interaction between DAT and D2R, which can increase locomotor activity in mice [25]. Given the therapeutic effects of DAT blockers and stimulant agents (e.g. methylphenidate) in ADHD, we hypothesize that the disruption of D2R-DAT protein complex might be a new treatment means for ADHD by enhancing the dopaminergic neurotransmission. Thus, the ultimate goal of the current study was to investigate the potential effects of TAT-DAT $\mathrm{NT}_{\mathrm{NT}}$ in an animal model of ADHD. In the current literature, the spontaneously hypertensive rats (SHR) is one of the most widely-used and validated animal models of ADHD [29, 30]. Before we investigated the effects of TAT-DAT ${ }_{\mathrm{NT}}$ in SHR rats, we hoped to rule out the possibility that TAT-DAT ${ }_{\mathrm{NT}}$ may act differently in rats compare to mice. Therefore, we began our study by confirming whether the disruption of D2R-DAT protein complex by TAT-DAT $\mathrm{TT}_{\mathrm{NT}}$ enhances the locomotor activity in rats.

In Fig. 1a, normal SD rats were placed in open field boxes to compare baseline and peptide-induced locomotor activities among the three treatment groups $(n=$ 6-8 animals per group). The three groups did not differ in baseline level $(p=\mathrm{NS})$. Subsequently, we administered their respective treatments (i.e. saline, TAT-DAT $\mathrm{NT}_{\mathrm{NT}}$ or TAT) intracranially. Thirty minutes after the administration, we tracked their locomotor activities for another $30 \mathrm{~min}$ and discovered that $\mathrm{SD}$ rats treated with TAT-DAT $_{\mathrm{NT}}(40 \mathrm{nmol})$ exhibited a higher level of locomotion activity. Two-way ANOVA analysis revealed significant treatment effect on locomotor activity $\left(\mathrm{F}_{2,44}=\right.$ 29.0, $p<0.001$ ), and Bonferroni post-hoc analysis confirmed that TAT-DAT ${ }_{\mathrm{NT}}$ treatment were statistically different from both saline and TAT treatment $(p<0.001)$.

The locomotor data were further divided and analyzed at each of the six five-minute intervals as shown in Fig. 1b. Two-way repeated measure ANOVA analysis revealed a significant time $\left(\mathrm{F}_{1.39}, 24.863=8.02, p<0.01\right)$ and treatment $\left(\mathrm{F}_{2,19}=26.827, p<0.001\right)$ effect on locomotor activity. However, no significant time $\times$ treatment interaction $\left(F_{10}, 96=0.291, p=0.891\right)$ effect were detected. Furthermore, Bonferroni post-hoc analysis also confirmed that the TAT-DAT ${ }_{\mathrm{NT}}$ peptide significantly elevated voluntary movement across all six time-points compared to both saline and TAT control peptide $(p<$ 0.01 or less; Fig. 1b).

To confirm that the stimulant effect of TAT-DAT $\mathrm{NT}_{\mathrm{N}}$ was due to its disruptive actions on D2R-DAT protein complexes, we performed co-immunoprecipitation using striatal brain tissues from SD rats that received the treatments. Ideally, we would like to use tissues from nucleus accumbens core (NAc), a region responsible for locomotor behavior, for this co-immunoprecipitation experiment, but NAc alone might not yield enough proteins to practically perform this assay. Since NAc is also considered a part of striatum, we decided to use striatal tissues, which include NAc, for our co-immunoprecipitation experiment. Co-immunoprecipitation showed that TAT-DAT $_{\mathrm{NT}}$ disrupted the D2R-DAT complex in SD rats, as compared to those from TAT- or saline-injected groups (Fig. 1c). In this co-immunoprecipitation assay, we used total protein extracts as a positive control and naïve IgG as a negative control. The direct immuno-precipitated D2R (i.e. the lower panel of Fig. 1c) serves as a control to ensure that equal amount of D2R was present in each sample and that the differences in co-immunoprecipitation of DAT were due to changes in the degree of D2R-DAT interaction, rather than antibody artifacts. In Fig. 1d, densitometric analysis revealed that the co-immunoprecipitation of DAT (DAT CoIP) by D2R antibody was significantly lower in SD rats injection with TAT-DAT $\mathrm{NT}_{\mathrm{N}}$ as compared to those injected with saline and TAT alone (one-way ANOVA with Bonferroni post-hoc analysis, $\mathrm{F}_{2,8}=10.398$, $p<0.05)$. We also examined the level of immunoprecipitation of D2R (D2R IP) and found no difference among the three groups (one-way ANOVA, $\mathrm{F}_{2,8}=3.87, p=\mathrm{NS}$; Fig. 1e). After determining the ratio between DAT CoIP and D2R IP for each sample, we further confirmed the reduc-

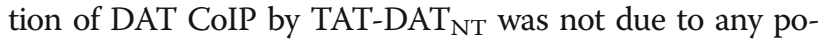
tential difference in D2R IP (one-way ANOVA with Bonferroni post-hoc analysis, $\mathrm{F}_{2,8}=9.01, p<0.05$; Fig. 1f). These results showed that TAT-DAT ${ }_{\mathrm{NT}}$, by disrupting the D2R-DAT interaction, leads to increased locomotor behavior in SD rats.

\section{AMPT-mediated dopamine depletion model}

Our next objective was to investigate whether

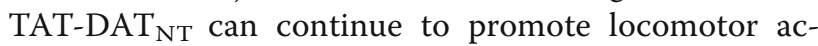
tivity even when endogenous dopamine level was low. Before we could continue our investigation, however, we wished to validate a published dopamine depletion model [25]. This model was adapted from McDougall et al. [25], they reported that animals pre-treated with 

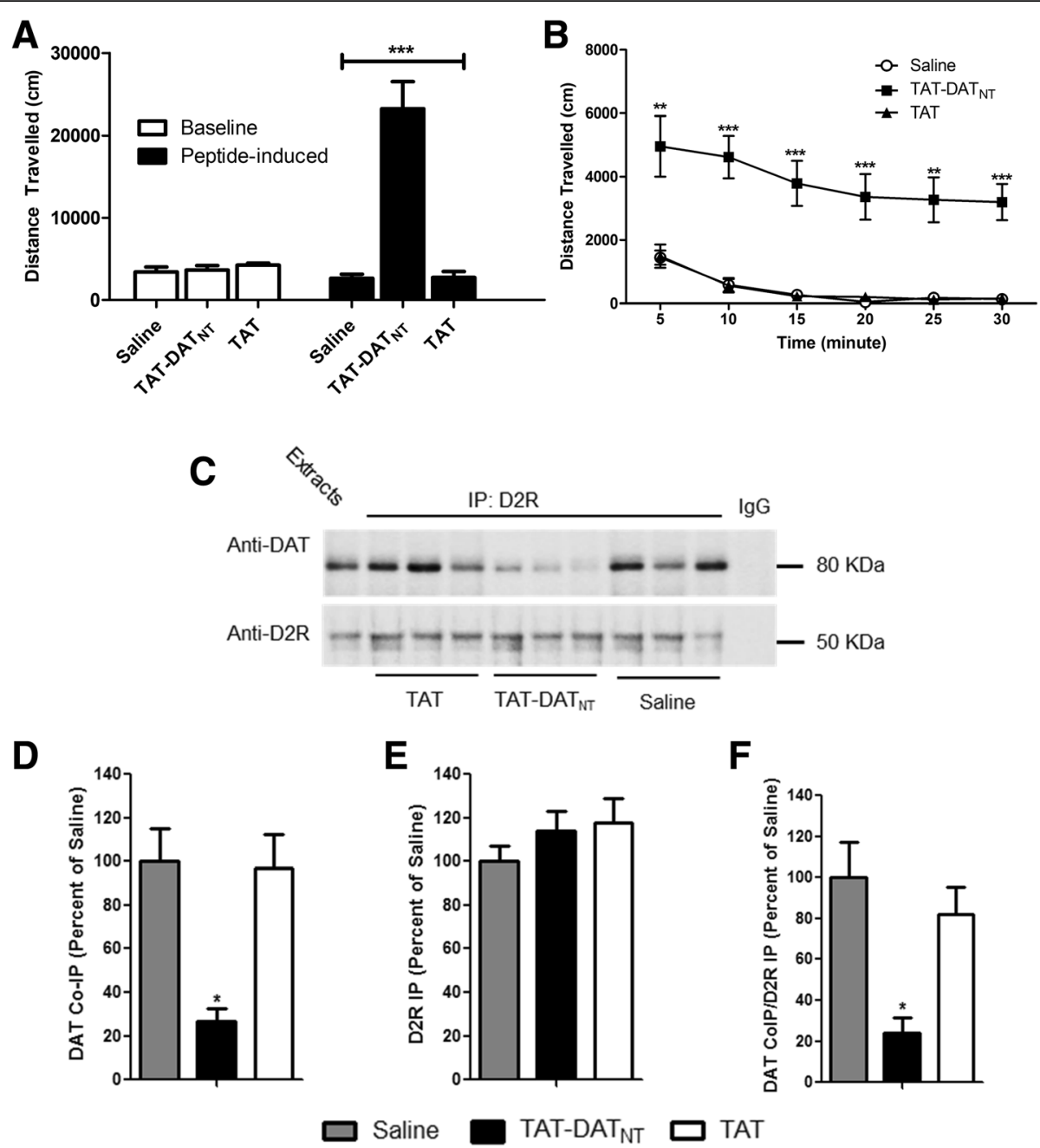

$\mathbf{F}$

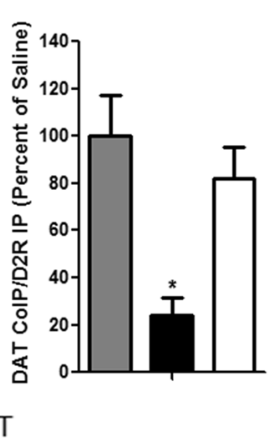

Fig. 1 The disruption of D2R-DAT protein complex stimulates voluntary movement of SD rats. a-b The effects of TAT-DAT on locomotor behavior ( $n=6-8$ animals per group). a Thirty minutes after the peptide administration, SD rats treated with TAT-DAT NT $_{\text {(at }}$ $40 \mathrm{nmol}$, i.c.v.) exhibited a significantly higher level of locomotor activity compared to those treated with saline or TAT $(p<0.001)$. b The stimulant effects of TAT-DAT NT $_{\text {T }}$ were significant across all six time intervals compared to both saline and TAT, indicating that the difference in locomotor activity is unlikely novelty-driven. $\mathbf{c}-\mathbf{f}$ The effects of TAT-DAT ${ }_{N T}$ on the D2R-DAT protein interaction ( $n=3$ per group). $\mathbf{c}$ Coimmunoprecipitation showed that TAT-DAT ${ }_{N T}$ disrupts the D2R-DAT complex in SD rats, as compared to those from TAT- or saline-injected group. d-f Densitometric analysis of DAT co-immunoprecipitation (DAT CoIP) and D2R immunoprecipitation (D2R IP) from striatal lysate of SD rats injected with saline, TAT, or TAT-DAT NT peptide. Results for each sample are presented as the ratio of the saline group. Data were analyzed by one-way ANOVA followed by Tukey's test. ${ }^{*} p<0.05,{ }^{* *} p<0.01,{ }^{* * *} p<0.001$. Data are shown as mean \pm S.E.M

AMPT showed lower locomotor activity, which was further confirmed by another research group [31]. We chose this partial depletion model because hypo-dopaminergic activity, rather than complete lack of dopamine, is implicated with the patho-physiology of ADHD. Therefore, we believed this AMPT-mediated partial dopamine depletion model was more suitable for our study rather than a complete deletion model, before we moved to a more widely-used model of ADHD --- spontaneously hypertensive rats.

In order to validate this dopamine-depletion model, we had animals from both vehicle and AMPT groups placed in open-field chambers on three consecutive days to record their baseline locomotor activity. Following the injection of either vehicle or AMPT, animals were returned to open field boxes to track their locomotor activities for $30 \mathrm{~min}$. Two-way ANOVA reported significant injection effect $\left(\mathrm{F}_{1,18}=11.02, p<0.01\right)$. The vehicle group did not differ in locomotor activity between baseline and post-injection (Bonferroni post-hoc analysis, $p=$ NS; Fig. 2a), whereas the post-injection locomotor activity in the AMPT group was significantly lower than its baseline level, approximately a 50\% reduction (Fig. 2a; $p<0.01)$. 

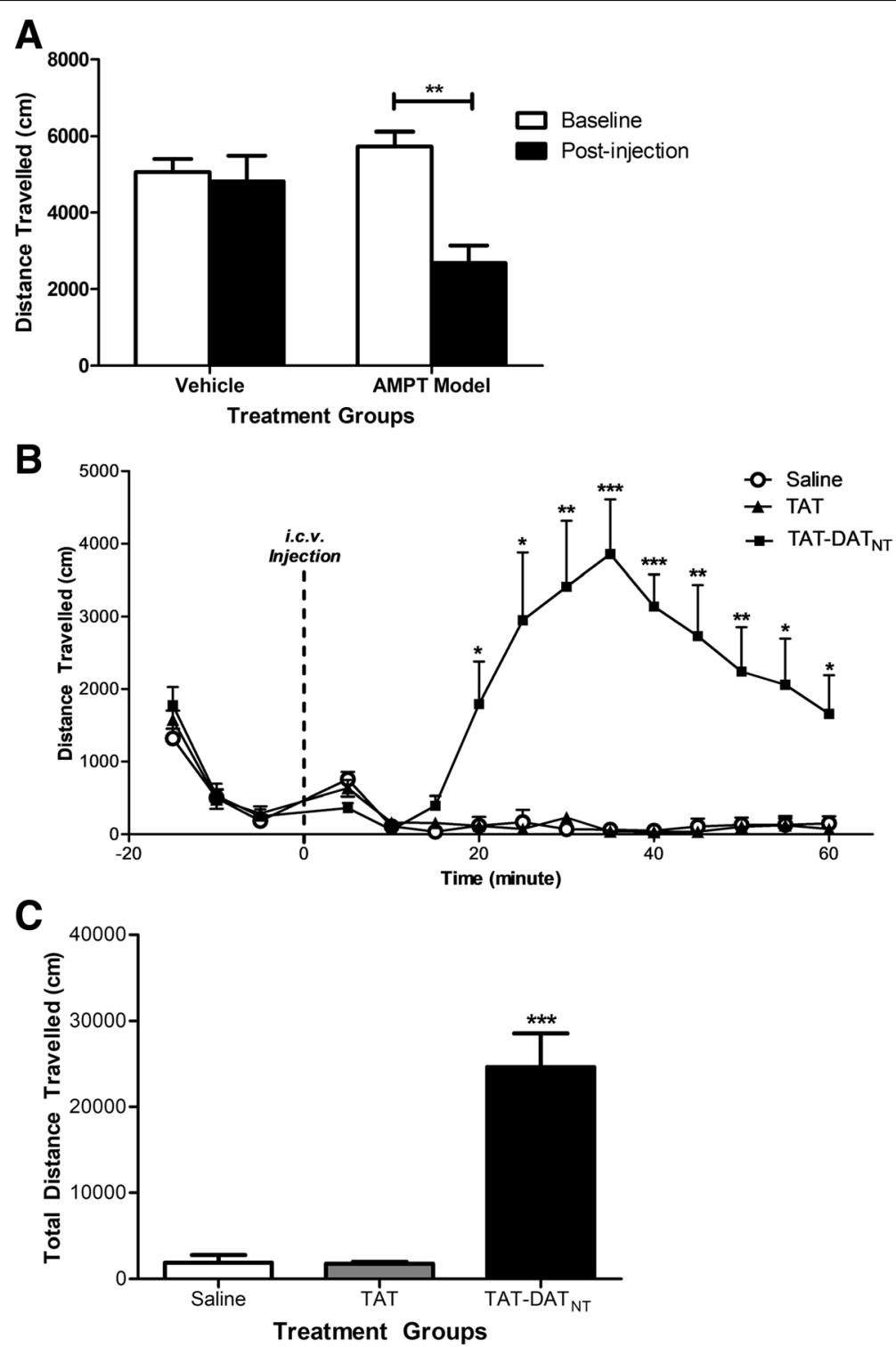

Fig. 2 The disruption of D2R-DAT by TAT-DAT ${ }_{N T}$ rescues the locomotor impairment imposed by AMPT-mediated dopamine depletion. a The AMPT treatment significantly impaired locomotor activity compared to vehicle ( $n=5-6$ per group). $\mathbf{b}$ A timewise graph illustrates the locomotor activities of dopamine-depleted animals injected with saline, TAT or TAT-DAT NT $\left(n=6-8\right.$ per group). c TAT-DAT NT $_{\text {( }} 40$ nmol, i.c.v.) significantly elevated the locomotor movement in the dopamine-depleted animals. All data were presented as mean \pm SEM. ${ }^{*}, p<0.05 ;{ }^{* *}, p<0.01 ;{ }^{* * *}, p<0.001$

\section{The effects of D2R-DAT disruption in DA-depleted} animals

We next examined whether dopamine depletion can affect the ability of TAT-DAT ${ }_{\mathrm{NT}}$ to promote locomotor behavior. Animals ( $n=6-8$ per group) were treated with AMPT to cause dopamine depletion and were placed in open-field chambers for $15 \mathrm{~min}$. Then, animals received their i.c.v. injections (i.e. saline, TAT, TAT-DAT $\mathrm{NT}_{\mathrm{NT}}$ ) and were immediately returned to the open-field chambers for 1 hour.

One-way ANOVA analysis revealed significant treatment effect on the total locomotor activity $\left(\mathrm{F}_{2,20}=\right.$
26.10, $p<0.001$; Fig. 2c), where animals treated with TAT-DAT $_{\mathrm{NT}}$ exhibited a significantly higher level of locomotion (Bonferroni post-hoc analysis, $p<0.001$ ).

The hourly locomotor activity was further analyzed at each five-minute interval (Fig. 2b). Two-way ANOVA with repeated measures confirmed treatment effect $\left(\mathrm{F}_{2}\right.$, $\left.{ }_{18}=29.63, p<0.001\right)$ and time effect $\left(\mathrm{F}_{2.66}, 47.85=4.58\right.$, $p<0.01)$. TAT-DAT ${ }_{\mathrm{NT}}$ began to elevate locomotor behavior approximately $20 \mathrm{~min}$ after administration and its stimulant effect lasted throughout the remainder of the experiment (Bonferroni post-hoc analysis, $p<0.05$ or less). Consequently, this experiment confirmed that dopamine 
depletion does not abolish the ability of D2R-DAT disruption to promote dopamine-driven behavior.

\section{The effects of D2R-DAT disruption on extracellular dopamine}

Next, we performed an in vivo microdialysis study to investigate whether the disruption of D2R-DAT protein complex by TAT-DAT $\mathrm{NT}_{\mathrm{NT}}$ increases extracellular level the nucleus accumbens core (NAc), part of the ventral striatum, which can explain the stimulant effects of TAT-DAT $_{\mathrm{NT}}$ observed previously. It has been widely reported that nucleus accumbens core (NAc) is essential for mediating locomotor movements in rodents [32-34]. As shown in Fig. 3a, we placed a guide cannula into the lateral ventricle for the administration of either TAT or TAT-DAT $_{\mathrm{NT}}$ peptide, whereas a microdialysis cannula was implanted into the nucleus accumbens core for the collection of dialysates. We used high-performance liquid chromatography to analyze the dopamine content in each dialysate, and the retention time of dopamine was determined to be at $5.08 \mathrm{~min}$ (Fig. 3b). Prior to the injection of either peptide treatment, dialysates were continually collected for 2 hours to determine the basal extracellular dopamine level. As illustrated in Fig. 3c, both groups ( $n=5-6$ per group) displayed a similar baseline of extracellular dopamine level $(p=\mathrm{NS})$. Two-way ANOVA with repeated measures revealed that no significant treatment $\left(\mathrm{F}_{1,9}=0.112, p=\mathrm{NS}\right)$, no time effect $\left(\mathrm{F}_{3,27}=1.174, p=\mathrm{NS}\right)$ and no treatment $\times$ time effect $\left(\mathrm{F}_{3,27}=1.926, p=\mathrm{NS}\right)$.

Following the i.c.v. administration, TAT-DAT $\mathrm{NT}_{\mathrm{NT}}$, at the dose of $40 \mathrm{nmol}$ (i.c.v.), increased the extracellular NAc dopamine level (Fig. 3b). Two-way ANOVA with repeated measures reported significant time effect $\left(\mathrm{F}_{4}\right.$, $\left.{ }_{36}=9.23, p<0.001\right)$, treatment effect $\left(F_{1,9}=38.31\right.$, $p<0.001)$ and time $\times$ treatment effect $\left(\mathrm{F}_{4,36}=18.65\right.$, $p<0.001)$. Compared to the treatment of TAT, the i.c.v. injection of $\mathrm{TAT}^{-\mathrm{DAT}_{\mathrm{NT}}}$ significantly elevated extracellular NAc dopamine content and the significant increase lasted for 2 hours (Bonferroni post-hoc analysis, $p<0.05$ or less; Fig. 3c). Overall, this in vivo microdialysis study provided strong evidence that the disruption of D2R-DAT by the TAT-DAT $\mathrm{NT}_{\mathrm{NT}}$ peptide results in an increased extracellular dopamine level.

\section{The Effects of TAT-DAT ${ }_{\mathrm{NT}}$ on Hyperactivity in SHR rats}

The spontaneously hypertensive rat (SHR), a commonly used animal model of attention deficit/hyperactivity disorder (ADHD) [35], is genetically bred from progenitor Wistar Kyoto rat (WKY) [36]. The SHR rats exhibit similar behavioral characteristics as children with ADHD such as hyperactivity $[29,37,38]$. Since the current stimulant treatments (e.g. methylphenidate) for ADHD all strengthen synaptic dopamine signaling [39], we examined the effects of the TAT-DAT $\mathrm{NT}_{\mathrm{N}}$ on the hyperactivity of SHR rats and we hypothesized that this peptide will reverse such hyperactivity by disrupting the D2R-DAT interaction.

WKY rats were included in this study as a negative control strain for the hyperactivity of SHR rats. All WKY and SHR rats were placed in the locomotor boxes for two consecutive days to determine their baseline locomotor activities. As illustrated in Fig. 4a, SHR rats exhibited locomotor hyperactivity compared to WKY rats, which two-way ANOVA confirmed significant strain effect $\left(F_{1,20}=233.2, p<0.001\right)$.

To avoid hypertension as a potential confounding factor, we decided to test the SHR rats and WKY rats at 4 weeks old, and therefore they were a lot smaller compared to the SD rats in the previous experiment. As a result, we chose a lower dose $(0.4 \mathrm{nmol}$, i.c.v. $)$ of TAT-DAT $_{\mathrm{NT}}$ to test its effects on the locomotor behavior in these animals. In Fig. 4b, TAT-DAT $\mathrm{NT}_{\mathrm{NT}}$ significantly decreased the locomotor activity in SHR compared to TAT $(p<0.01)$ but had no effects in WKY rats $(p=$ NS). At $4 \mathrm{nmol}$, however, TAT-DAT $\mathrm{NT}_{\mathrm{N}}$ exacerbated the hyperactivity of SHR rats $(p<0.01$; Fig. 4c). Altogether, TAT-DAT $_{\mathrm{NT}}$ displayed a U-shaped dose-response curve in SHR rats as shown in Fig. 4d, where it alleviated hyperactivity at low dose, but worsened such behavioral abnormality at a higher dose.

To verify the peptide effects were due to the disruption of D2R-DAT complex, we performed co-immunoprecipitation using striatal brain tissues from SHR rats that received the treatments. As illustrated in Fig. 4e, the administration of TAT-DAT $\mathrm{NT}_{\mathrm{NT}}$ reduced the level of D2R-DAT interaction in SHR rats, as compared to those treated with TAT. The densitometric analysis quantified that the TAT-DAT ${ }_{\mathrm{NT}}$ peptide significantly reduced the level of D2R-DAT complex as compared to TAT group $\left(t_{5}=3.69, p<0.05\right.$; Fig. $\left.4 \mathrm{f}\right)$. We also examined the level of immunoprecipitation of D2R (D2R IP) and found no difference between the two groups $\left(t_{5}=\right.$ $0.36, p=$ NS; Fig. $4 \mathrm{~g})$. Finally, we also determined the ratio between DAT CoIP and D2R IP, and confirmed that the lower DAT CoIP in animals treated with TAT-DAT $_{\mathrm{NT}}$ was not due to any potential difference in D2R IP $\left(t_{5}=2.79, p<0.05\right.$; Fig. $\left.4 \mathrm{~h}\right)$. These data confirmed that the TAT-DAT ${ }_{\mathrm{NT}}$ peptide can rescue the locomotor hyperactivity in SHR rats by disrupting the D2R-DAT interaction.

\section{The effects of TAT-DAT ${ }_{N T}$ on spontaneous alternation behavior (SAB) in SHR rats}

Aside from hyperactivity, SHR rats also display lower spontaneous alternation behavior (SAB) in a Y-maze test [40-42]. We were interested in examining whether the administration of TAT-DAT $_{\mathrm{NT}}$ can improve such 


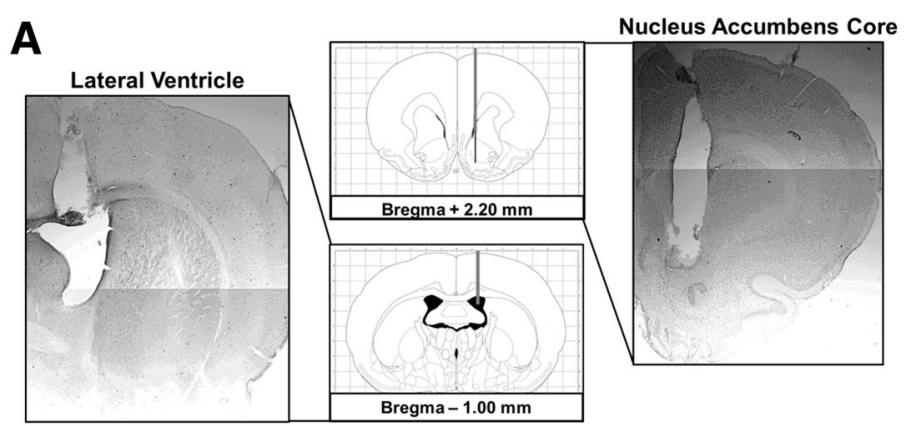

B
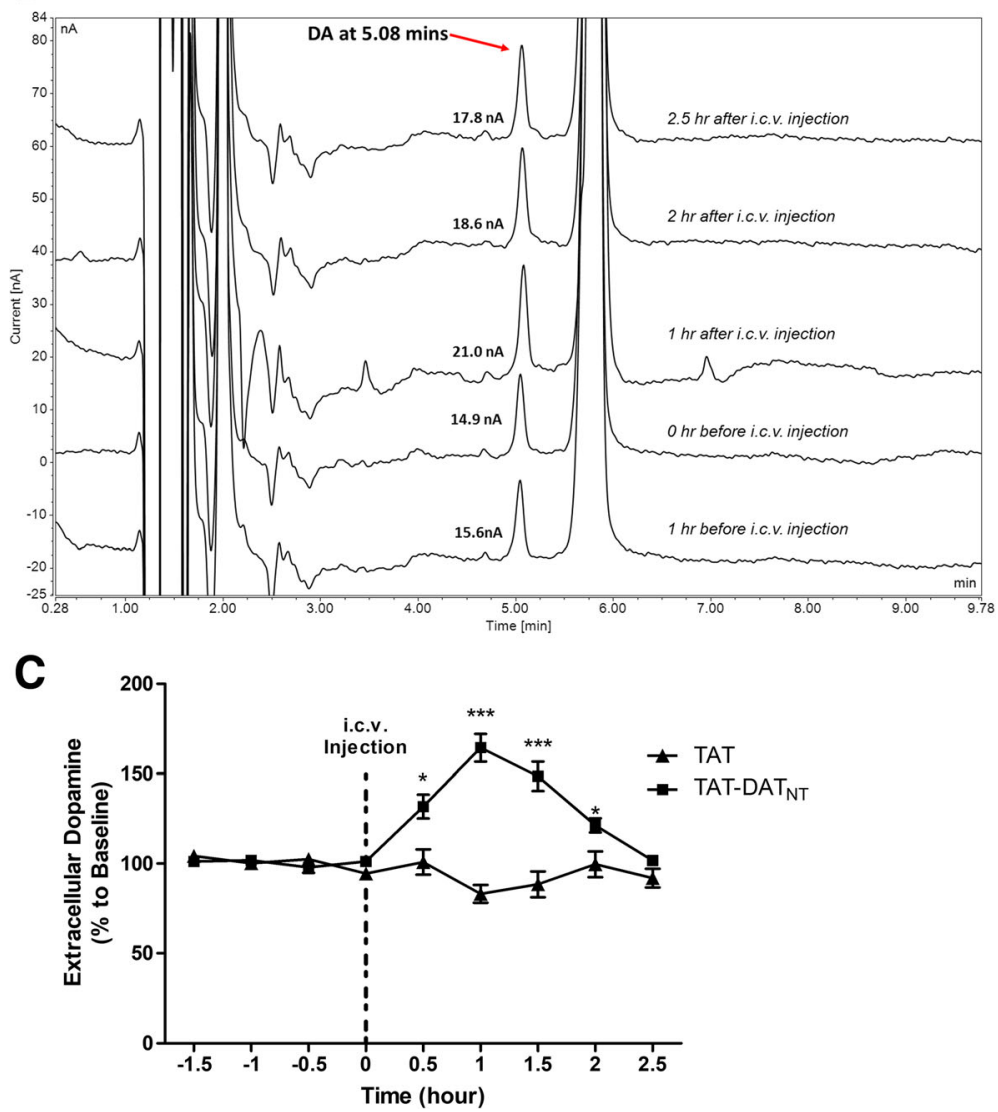

Fig. 3 The stimulant effect of D2R-DAT disruption is due to the rise of extracellular dopamine level in SD rats. a Schematic illustration and cresyl violet staining confirmation of cannula placement into both the lateral ventricle and nucleus accumbens core. The grey bars represent the cannula, whereas the black bar represents the 2-mm probe membrane. b Time-course raw traces of high performance liquid chromatography before and after the administration of TAT-DAT ${ }_{N T}$ was illustrated. The retention time of dopamine was determined to be at 5.08 min. C TAT-DATNT $(40 \mathrm{nmol}$, i.c.v.) started to increase the extracellular dopamine level half an hour after its administration and such effect remained significant approximately for 2 hours $(n=5-6)$. The dotted line represented the time of intra-cranial injection. All data were presented as percent dopamine to baseline (\%) \pm SEM. ${ }^{*} p<0.05,{ }^{* *} p<0.01$ and ${ }^{* * *} p<0.001$

behavior deficits in SHR rats using the same Y-maze test. In this test, animals could explore all three arms freely (Additional file 1: Figure S1A). A spontaneous alternation is made when an animal visit three different arms in three consecutive arm entries.

SHR rats treated with TAT-DAT $\mathrm{NT}_{\mathrm{N}}(0.4 \mathrm{nmol}$, i.c.v. $)$ showed a significantly higher percentage of spontaneous alternation behavior compared to their TAT counterparts (two-tailed t-test, $\mathrm{t}_{10}=2.422, p<0.05$; Additional file 1: Figure S1B). As illustrated in Additional file 1: Figure $\mathrm{S} 1 \mathrm{C}$, animals from both TAT and TAT-DAT $\mathrm{NT}_{\mathrm{NT}}$ did not differ in time spent in each duration (two-way ANOVA with repeated measures, $\mathrm{F}_{1,10}=0.321, p=\mathrm{NS}$ ), suggesting that the differences in spontaneous 

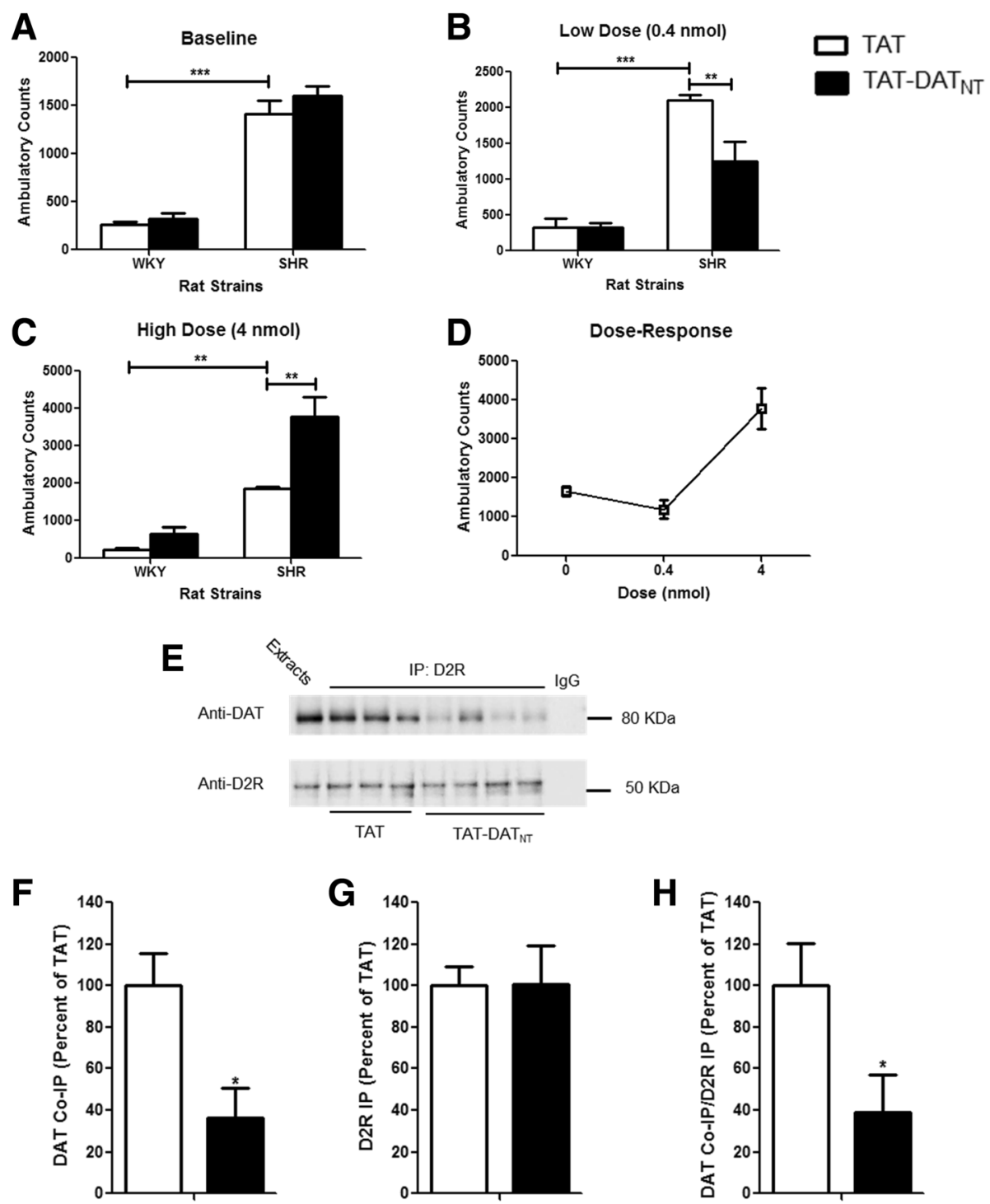

G
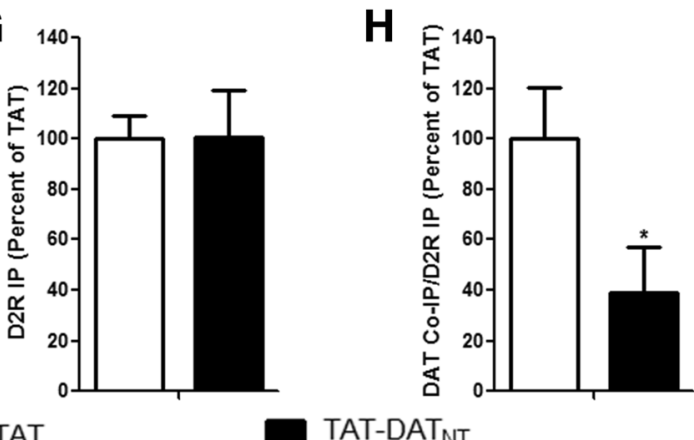

Fig. 4 TAT-DATNT alleviated the hyperactivity of spontaneously hypertension rats. a-d The effects of TAT-DAT behavior in WKY and SHR rats ( $n=6-8$ per group). a SHR rats manifested a significantly higher level of baseline locomotor activity compared to the control strain WKY rats $(p<0.001)$. b TAT-DAT $\mathrm{NT}$, at 0.4 nmol, alleviated the hyperactivity of SHR rats as compared to the TAT control $(p<$ 0.01). c TAT-DAT $T_{N T}$ at 4 nmol exacerbated the hyperactivity of SHR rats compared to the TAT-treated SHR rats $(p<0.01)$. d TAT-DAT T $_{\text {Tisplayed }}$ an U-shaped dose-response curve in SHR rats. $\mathbf{e}-\mathbf{h}$ The effects of TAT-DAT $N$ (at $0.4 \mathrm{nmol}$ ) on the D2R-DAT interaction in SHR rats ( $\mathrm{n}=3$ for TAT, and 4 for TAT-DAT ${ }_{N T}$ ). e TAT-DAT $T_{N T}$ reduced the level of D2R-DAT complex in SHR rats, as compared to those from TAT-injected group. $\mathbf{f}-\mathbf{h}$ Densitometric analysis of DAT co-immunoprecipitation (CoIP) and D2R immunoprecipitation (D2R IP) from striatal lysate of SHR rats injected with TAT, or TAT-DAT NT peptide. Results for each sample are presented as the ratio of the TAT samples. Data were analyzed by t-test. ${ }^{*} p<0.05,{ }^{* *} p<$ $0.01,{ }^{* *} p<0.001$. Data are shown as mean \pm S.E.M

alternation behavior were unlikely due to confounding factors such as anxiety.

\section{Discussion}

Dopamine transporter (DAT) facilitates the reuptake of dopamine from the synaptic cleft into the presynaptic neuronal terminal, playing a crucial role in regulating dopaminergic signaling. The importance of DAT in dopaminergic signaling was further reiterated by Jones et al. as they suggested that the lifespan of synaptic dopamine prolongs by approximately 300 times and the synaptic dopamine content increases by 5 times in the absence of DAT [43]. The actions of DAT can be regulated by a wide range of factors and cellular events and 
can be summarized in three main categories: 1) ligand-binding (e.g. substrates and inhibitors), 2) enzymatic modification, and 3) protein-protein interaction.

On the same presynaptic terminus of dopaminergic neurons, there are dopamine D2 receptors (D2R) serving as a presynaptic auto-inhibitory receptor, which is implicated in the regulation of DAT functions. We previously discovered that, regardless of its activation state, D2R can enhance the membrane expression of DAT and consequently DAT-mediated reuptake of dopamine through their direct protein-protein interaction [23]. Structurally, this interaction is mediated through the first 15 amino acids of the N-terminus of DAT, which sequence was used to generate the interfering peptide (i.e. TAT-DAT $_{\mathrm{NT}}$ ) in this study. Interestingly, the first 22 amino acids of the $\mathrm{N}$-terminus are essential for protein kinase C-mediated phosphorylation of DAT [44]. Therefore, it is possible that D2R promotes the actions of DAT by masking the $\mathrm{N}$-terminus from the regulatory phosphorylation. Although our previous study of D2R-DAT interaction was conducted in mouse tissues, we have confirmed the existence of D2R-DAT interaction using rat striatal tissue and that TAT-DAT $\mathrm{NT}_{\mathrm{NT}}$ peptide was able to disrupt the D2R-DAT interaction in this study (Fig. 1c). We also observed that TAT-DAT $\mathrm{NT}_{\mathrm{NT}}$ decrease dopamine reuptake in rat primary cultures in our previous study [23]. Moreover, the region of DAT $\left(\mathrm{M}_{1}\right.$ $\mathrm{V}_{15}$ : MSKSKCSVGPMSSVV) responsible for mediating the interaction with D2R is identical between mice and rats, which the same amino acid sequence was used to synthesized TAT-DAT ${ }_{\mathrm{NT}}$. Thus, the ability of TAT-DAT $_{\mathrm{NT}}$ to disrupt the D2R-DAT interaction should not be altered, which was confirmed by our results in Fig. 1c. In addition, using the BLAST tool of PubMed (N.I.H.), we confirmed that this amino acid sequence of $\mathrm{TAT}_{-\mathrm{DAT}}$ NT was only found in dopamine transporter, but not in norepinephrine transporter (NET) and serotonin transporter (SERT) (species: Rattus norvegicus). Therefore, we do not expect that TAT-DAT ${ }_{\mathrm{NT}}$ will affect NET and SERT.

Since dopamine is critically involved in movement initiation and facilitation through its actions on both direct and indirect pathways in the basal ganglia circuitry [45-47], it is plausible to presume that a higher extracellular dopamine level should equate behavioral alterations such as an elevated level of voluntary movements. This is exactly the effects TAT-DAT $\mathrm{NT}_{\mathrm{N}}$ observed in this study. The disruption of D2R-DAT by the intracranial administration of TAT-DAT $\mathrm{NT}_{\mathrm{NT}}$ results in a significantly higher level of locomotor activity than the control groups $(p<0.001$; Fig. 1a). The locomotor activities of animals from the TAT-DAT $\mathrm{NT}_{\mathrm{NT}}$ group were significantly elevated at all six time-points compared to both saline and TAT groups $(p<0.001$;
Fig. 1b). It prompted that the differences in locomotor behavior were not due to novelty since the novelty-induced hyperactivity is usually observed within the first 5-10 min and dramatically normalize afterwards. Moreover, all the animals habituated to the open-field boxes on three consecutive days prior to the testing, therefore minimizing the effects of novelty as a potential confounding factor. Such dramatic enhancement in locomotor behavior further emphasized the critical roles of DAT-mediated reuptake in the termination of dopaminergic neurotransmission. Similarly, hyperactivity due to elevated dopamine content in the synapse has been reported in mice lacking DAT [48] and rats with pharmacological blockade of DAT [49, 50].

We were also interested in whether the D2R-DAT disruption can strengthen dopamine signaling even under hypo-dopaminergic signaling. Hence, we examined the effects of TAT-DAT $\mathrm{NT}_{\mathrm{N}}$ in an acute dopamine depletion model. AMPT exerts its inhibitory actions on tyrosine hydroxylase, which will lead to a severe impairment in the endogenous production of dopamine $[25,31]$. In this model, the disruption of D2R-DAT also sufficed to alleviate the AMPT-induced impairment on locomotor behavior ( $p<0.001$; Fig. 2b and c).

Based on the data from both normal and dopamine-depleted animals, we hoped to confirm that the disruption of D2R-DAT stimulates locomotor behavior by directly enhancing dopaminergic neurotransmission. Therefore, we decided to employ in vivo microdialysis to ensure the behavior effects observed in rodents were due to a rise in extracellular dopamine level. We targeted the nucleus accumbens core (NAc) because this region is considered to essentially mediate voluntary locomotor movement in rodents [32-34]. As we hypothesized, the interference by TAT-DAT $\mathrm{NT}_{\mathrm{NT}}$, at the dose of $40 \mathrm{nmol}$, rendered a significant rise in extracellular dopamine $(p<0.001)$, and which lasted for approximately 2 hours (Fig. 3c). Since we do not expect that TAT-DAT $_{\mathrm{NT}}$ would have opposite effects at different doses, we did not perform in vivo microdialysis for different doses of TAT-DAT $\mathrm{NT}_{\mathrm{T}}$.

As mentioned in the introduction, dysregulation of dopaminergic system has been implicated in attention deficit hyperactivity disorder (ADHD), which is characterized by hyperactivity, impaired working memory, impulsivity and inattention [51-53]. It is postulated that ADHD may result from deficits in the dopaminergic system in cortical brain structures such as the prefrontal cortex, subcortical areas such as striatum [54, 55]. Particularly, the dopamine transporter (DAT) has drawn a lot of attention as a suitable candidate for treating ADHD. For instance, the mainstay medication for ADHD is stimulants that block DAT to achieve their 
therapeutic effects [56-58]. In addition, neuroimaging studies of patients with ADHD reported an elevated level of striatal dopamine transporter activity, which is reverted by the administration of methylphenidate [59, 60]. Given the implication of dopamine dysregulation and dopamine transporter in ADHD, we are curious about whether the D2R-DAT protein complex will prove to be a viable therapeutic target for ADHD. Therefore, we investigated whether the disruption of D2R-DAT can exert any beneficial effects on the ADHD-like symptoms (i.e. hyperactivity and impaired working memory) in a widely used rodent model of ADHD -.- spontaneously hypertensive rats (SHR) [35, 36]. It is widely believed that methylphenidate produces its therapeutic effects in ADHD by increasing dopamine level, which is similar to the actions of TAT-DAT $\mathrm{NT}_{\mathrm{NT}}$ as supported the microdialysis data (Fig. 3C). TAT-DAT ${ }_{\mathrm{NT}}$ alleviated hyperactivity in SHR rats (Fig. 4B), suggesting that enhancement in the dopaminergic neurotransmission can exert therapeutic effects on symptoms of ADHD. However, there are reports that, unlike its low dose, high dose of methylphenidate fails to offer the same therapeutic effects on hyperactivity in SHR rats [41, 61]. We also made similar observations at a higher dose of TAT-DAT $\mathrm{NT}_{\mathrm{NT}}$ (i.e. $4.0 \mathrm{nmol}$ ) in SHR rats, demonstrating a U-shaped dose-response curve on the hyperactivity in SHR (Fig. 4D). We believe this U-shaped dose-response curve occurs due to the possibility that low-dosed TAT-DAT $\mathrm{NT}_{\mathrm{NT}}$ returns the abnormally low level of dopaminergic signaling to the physiological range, and therefore normalizes the hyperactivity of SHR rats. However, when there is too much TAT-DAT ${ }_{\mathrm{NT}}$, it may excessively enhance dopaminergic neurotransmission and rather exerts its stimulant effects as observed in SHR rats (Fig. 4c).

WKY rats were included in the study as a control strain for SHR rats. Although one study reported a higher level of DAT in the striatum of SHR rats than WKY rats when they were 2-week old [62], overall no significant difference in the levels of D2R or DAT was reported between SHR and WKY rats. TAT-DAT $\mathrm{NT}_{\mathrm{N}}$, at neither $0.4 \mathrm{nmol}$ nor $4.0 \mathrm{nmol}$, elicited any effects on locomotor activity in the WKY rats. Similar to the effects of TAT-DAT ${ }_{\mathrm{NT}}$, the effects of methylphenidate on WKY rats are also dose-dependent $[63,64]$. At a dose (i.e. $0.6 \mathrm{mg} / \mathrm{kg}$ ) that is effective in SHR rats, methylphenidate dose not trigger any changes in the locomotor activity of WKY rats [63]. Methylphenidate can stimulate locomotor activity in WKY rats only when a much higher dose (e.g $2.5-10 \mathrm{mg} / \mathrm{kg}$ ) is given. The doses of TAT-DAT $_{\mathrm{NT}}$ tested in WKY rats were $0.4 \mathrm{nmol}$ and $4.0 \mathrm{nmol}$ per animals in our study, which therefore may not suffice to trigger stimulant effects in WKY rats.

Aside from hyperactivity, SHR rats are readily reported to exhibit low level of spontaneous alternation behavior in the
Y-maze test $[41,42]$. Here, we reported that TAT-DAT ${ }_{\mathrm{NT}}$ significantly enhanced spontaneous alternation behavior in SHR rats compared to those received TAT ( $p<0.05$; Additonal file 1: Figure S1B). Such improvement may be due to enhanced dopaminergic neurotransmission as studies have suggested that dopaminergic neurotransmission is involved in the manifestation of spontaneous alternation behavior. The chronic administration of haloperidol (i.e. a dopaminergic antagonist) decreases spontaneous alternation behavior [65], whereas methylphenidate (i.e. a dopaminergic stimulant) increases the same behavior [66].

It is worth noting that we used TAT peptide as the control peptide in this study rather than the second $\mathrm{N}$-terminus fragment of DAT $\left(\mathrm{A}_{16}-\mathrm{P}_{26}\right)$ from our previous study [23]. It has been reported that the $\mathrm{N}$-terminus of DAT is essential for protein kinase $\mathrm{C}$-mediated phosphorylation on serine residues [67], and the first 22 amino acids from the $\mathrm{N}$-terminus of DAT eliminate phosphorylation of DAT in response to PKC activation [44]. Since the second fragment of DAT covers part of the first 22 amino acids and contains serine residue, we were concerned that it may have unknown effects on DAT. Therefore, we chose to use TAT peptide as the control peptide instead. TAT peptide is also commonly used as a control peptide by other research groups [68-70] as well as our research group [71, 72]. On the other hand, there is a possibility that TAT-DAT $_{\mathrm{NT}}$, which main action is to disrupt the D2R-DAT interaction, may affect phosphorylation of DAT and other DAT-associated protein interactions. The investigation of TAT-DAT ${ }_{\mathrm{NT}}$ 's effects on DAT phosphorylation and other DAT-associated protein complexes will be the focus of our future studies.

Current therapies for ADHD block DAT and completely inhibit the reuptake of dopamine. Although they yield great clinical outcomes, they are also associated with serious adverse effects due to their complete blockade of DAT [39]. Here, we reported that a protein-protein interaction between dopamine D2 receptor (D2R) and dopamine transporter (DAT) provides a new way to modulate the activities of DAT and dopamine reuptake. Unlike conventional DAT blockers such as methylphenidate, the disruption of D2R-DAT leads to decreased membrane expression of DAT, while leaves the remaining DAT functional to facilitate the reuptake of dopamine [23]. We found that the disruption of this protein complex by an interfering peptide, namely TAT-DAT $_{\mathrm{NT}}$, increases extracellular dopamine level and therefore stimulate locomotor behavior in rats. Furthermore, at an appropriate dose, TAT-DAT $\mathrm{NT}_{\mathrm{NT}}$ alleviates hyperactivity and improves working memory in spontaneously hypertensive rats, an animal model of ADHD. Unlike typical DAT blockers, TAT-DAT ${ }_{\mathrm{NT}}$ specifically targets the D2R-DAT interaction and should possess no 
affinity for other transporters [39]. Although there may be concerns with its bioavailability in the brain, we have previously proved that intra-nasal delivery can be a viable route to counter this potential obstacle [73]. Hopefully, our findings altogether expand our current understanding of DAT regulation and its implication in ADHD and add values to future therapeutic development.

\section{Additional files}

Additional file 1: Figure S1. Low-dosed TAT-DAT $T_{N T}$ improved attention deficits in SHR rats. A, Schematic illustration of the Y-maze used in the study. B, TAT-DAT $\mathrm{NT}$ (0.4 nmol, i.c.v.) promoted spontaneously alternation behavior in SHR rats compared to the TAT control peptide ( $\mathrm{n}=6$ for each group). $\mathbf{C}$, Neither TAT nor TAT-DAT $T_{N T}$ caused SHR rats to spend more time or stay away from any arms ( $n=6$ per group). All data were presented as mean \pm SEM. ${ }^{*} p<0.05$ (TIF 2213 kb).

\section{Abbreviations}

ADHD: Attention Deficit/Hyperactivity Disorder; D2R: Dopamine D2 Receptor; DAT: Dopamine Transporter; SD: Sprague-Dawley Rats; SHR: Spontaneously Hypertensive Rats; WKY: Wistar Kyoto rats; NAc: Nucleus accumbens core

\section{Acknowledgements}

$\mathrm{TL}$ was supported by Ontario Graduate Scholarship for this project.

\section{Funding}

Not applicable

\section{Availability of data and materials}

The data that support the findings of this study are available from the corresponding author upon reasonable request.

\section{Authors' contributions}

TL and FL conceived and designed the experiments. TL conducted all the behavioral experiments, PS conducted the co-immunoprecipitation and western blotting, and $\mathrm{HZ}$ performed the HPLC analysis. TL, PS and $\mathrm{HZ}$ analyzed the data. TL wrote the article with the insightful advice from FL. All authors read and approved the final manuscript.

\section{Ethics approval and consent to participate}

Not applicable

\section{Consent for publication}

Not applicable

\section{Competing interests}

All authors have read the journal's authorship agreement and policy on disclosure of potential competing interest. The authors declare that they have no competing financial interests.

\section{Publisher's Note}

Springer Nature remains neutral with regard to jurisdictional claims in published maps and institutional affiliations.

\section{Author details}

${ }^{1}$ Campbell Family Mental Health Research Institute, Centre for Addiction and Mental Health, Toronto, ON M5T 1R8, Canada. ²Department of Physiology, University of Toronto, Toronto, ON, Canada. ${ }^{3}$ Department of Psychiatry, University of Toronto, Toronto, ON, Canada. ${ }^{4}$ Institute of Medical Science, University of Toronto, Toronto, ON, Canada.
Received: 21 September 2018 Accepted: 22 October 2018

Published online: 09 November 2018

\section{References}

1. Polanczyk GV, Salum GA, Sugaya LS, Caye A, Rohde LA. Annual research review: a meta-analysis of the worldwide prevalence of mental disorders in children and adolescents. J Child Psychol Psychiatry. 2015;56(3):345-65.

2. Polanczyk G, de Lima MS, Horta BL, Biederman J, Rohde LA. The worldwide prevalence of ADHD: a systematic review and metaregression analysis. Am J Psychiatry. 2007;164(6):942-8.

3. Sagvolden $T$, Johansen EB, Aase $H$, Russell VA. A dynamic developmental theory of attention-deficit/hyperactivity disorder (ADHD) predominantly hyperactive/impulsive and combined subtypes. Behav Brain Sci. 2005;28(3): 397-419 discussion-68.

4. Greenhill LL, Pliszka S, Dulcan MK, Bernet W, Arnold V, Beitchman J, et al. Practice parameter for the use of stimulant medications in the treatment of children, adolescents, and adults. J Am Acad Child Adolesc Psychiatry. 2002; 41(2 Suppl):26S-49S

5. Madras BK, Miller GM, Fischman AJ. The dopamine transporter and attention-deficit/hyperactivity disorder. Biol Psychiatry. 2005:57(11):1397-409.

6. Lambert NM, Hartsough CS. Prospective study of tobacco smoking and substance dependencies among samples of ADHD and non-ADHD participants. J Learn Disabil. 1998;31(6):533-44.

7. Vitiello B. Long-term effects of stimulant medications on the brain: possible relevance to the treatment of attention deficit hyperactivity disorder. J Child Adolesc Psychopharmacol. 2001;11(1):25-34.

8. Kollins SH, MacDonald EK, Rush CR. Assessing the abuse potential of methylphenidate in nonhuman and human subjects: a review. Pharmacol Biochem Behav. 2001;68(3):611-27.

9. Volkow ND, Ding YS, Fowler JS, Wang GJ, Logan J, Gatley JS, et al. Is methylphenidate like cocaine? Studies on their pharmacokinetics and distribution in the human brain. Arch Gen Psychiatry. 1995;52(6):456-63.

10. Fowler JS. Volkow ND. PET imaging studies in drug abuse. J Toxicol Clin Toxicol. 1998;36(3):163-74.

11. Volkow ND, Wang GJ, Fowler JS, Hitzemann R, Angrist B, Gatley SJ, et al. Association of methylphenidate-induced craving with changes in right striato-orbitofrontal metabolism in cocaine abusers: implications in addiction. Am J Psychiatry. 1999;156(1):19-26.

12. Mash DC, Pablo J, Ouyang Q, Hearn WL, Izenwasser S. Dopamine transport function is elevated in cocaine users. J Neurochem. 2002;81(2): 292-300.

13. Kuhar MJ, Pilotte NS. Neurochemical changes in cocaine withdrawal. Trends Pharmacol Sci. 1996;17(7):260-4.

14. Robinson TE, Berridge KC. Addiction. Annu Rev Psychol. 2003:54:25-53.

15. Zahniser NR, Sorkin A. Rapid regulation of the dopamine transporter: role in stimulant addiction? Neuropharmacology. 2004;47(Suppl 1):80-91.

16. Missale C, Nash SR, Robinson SW, Jaber M, Caron MG. Dopamine receptors: from structure to function. Physiol Rev. 1998:78(1):189-225.

17. Foster JD, Cervinski MA, Gorentla BK, Vaughan RA. Regulation of the dopamine transporter by phosphorylation. Handb Exp Pharmacol. 2006;175: 197-214.

18. Leviel V. Dopamine release mediated by the dopamine transporter, facts and consequences. J Neurochem. 2011;118(4):475-89.

19. Gu H, Wall SC, Rudnick G. Stable expression of biogenic amine transporters reveals differences in inhibitor sensitivity, kinetics, and ion dependence. J Biol Chem. 1994;269(10):7124-30

20. Gu HH, Wall S, Rudnick G. Ion coupling stoichiometry for the norepinephrine transporter in membrane vesicles from stably transfected cells. J Biol Chem. 1996:271(12):6911-6.

21. Lee FJ, Liu F, Pristupa ZB, Niznik HB. Direct binding and functional coupling of alpha-synuclein to the dopamine transporters accelerate dopamineinduced apoptosis. FASEB J. 2001;15(6):916-26.

22. Egana LA, Cuevas RA, Baust TB, Parra LA, Leak RK, Hochendoner S, et al. Physical and functional interaction between the dopamine transporter and the synaptic vesicle protein synaptogyrin-3. J Neurosci. 2009:29(14):4592-604

23. Lee FJ, Pei L, Moszczynska A, Vukusic B, Fletcher PJ, Liu F. Dopamine transporter cell surface localization facilitated by a direct interaction with the dopamine D2 receptor. EMBO J. 2007;26(8):2127-36.

24. Okamoto K. Spontaneous hypertension in rats. Int Rev Exp Pathol. 1969:7: 227-70. 
25. McDougall SA, Hernandez RM, Reichel CM, Farley CM. The partial D2like dopamine receptor agonist terguride acts as a functional antagonist in states of high and low dopaminergic tone: evidence from preweanling rats. Psychopharmacology. 2005;178(4):431-9.

26. Zhang H, Li T, Li S, Liu F. Cross-talk between alpha7 nAchR and NMDAR revealed by protein profiling. J Proteome. 2016;131:113-21.

27. Su P, Li S, Chen S, Lipina TV, Wang M, Lai TK, et al. A dopamine D2 receptor-DISC1 protein complex may contribute to antipsychotic-like effects. Neuron. 2014;84(6):1302-16.

28. Yan $Y$, Jiang $W$, Liu L, Wang $X$, Ding C, Tian $Z$, et al. Dopamine controls systemic inflammation through inhibition of NLRP3 inflammasome. Cell. 2015;160(1-2):62-73.

29. Sagvolden T, Johansen EB, Woien G, Walaas SI, Storm-Mathisen J, Bergersen $\mathrm{LH}$, et al. The spontaneously hypertensive rat model of ADHD--the importance of selecting the appropriate reference strain. Neuropharmacology. 2009;57(7-8):619-26.

30. Russell VA, Sagvolden T, Johansen EB. Animal models of attention-deficit hyperactivity disorder. Behav Brain Funct. 2005;1:9.

31. Fuentes $R$, Petersson $P$, Siesser WB, Caron MG, Nicolelis MA. Spinal cord stimulation restores locomotion in animal models of Parkinson's disease. Science. 2009:323(5921):1578-82.

32. Sellings LH, Clarke PB. Segregation of amphetamine reward and locomotor stimulation between nucleus accumbens medial shell and core. J Neurosci. 2003;23(15):6295-303.

33. Sellings LH, Clarke PB. 6-Hydroxydopamine lesions of nucleus accumbens core abolish amphetamine-induced conditioned activity. Synapse. 2006;59(6):374-7.

34. Boye SM, Grant RJ, Clarke PB. Disruption of dopaminergic neurotransmission in nucleus accumbens core inhibits the locomotor stimulant effects of nicotine and D-amphetamine in rats. Neuropharmacology. 2001;40(6):792-805.

35. Sagvolden T. Behavioral validation of the spontaneously hypertensive rat (SHR) as an animal model of attention-deficit/hyperactivity disorder (AD/HD). Neurosci Biobehav Rev. 2000;24(1):31-9.

36. Okamoto K, Aoki K. Development of a strain of spontaneously hypertensive rats. Jpn Circ J. 1963;27:282-93.

37. Sagvolden T, Russell VA, Aase H, Johansen EB, Farshbaf M. Rodent models of attention-deficit/hyperactivity disorder. Biol Psychiatry. 2005;57(11):123947.

38. Nakamura-Palacios EM, Caldas CK, Fiorini A, Chagas KD, Chagas KN, Vasquez EC. Deficits of spatial learning and working memory in spontaneously hypertensive rats. Behav Brain Res. 1996;74(1-2):217-27.

39. Spiller HA, Hays HL, Aleguas A, Jr. Overdose of drugs for attentiondeficit hyperactivity disorder: clinical presentation, mechanisms of toxicity, and management. CNS Drugs 2013;27(7):531-543.

40. Yoon SY, dela Pena I, Kim SM, Woo TS, Shin CY, Son KH, et al. Oroxylin a improves attention deficit hyperactivity disorder-like behaviors in the spontaneously hypertensive rat and inhibits reuptake of dopamine in vitro. Arch Pharm Res. 2013;36(1):134-40.

41. Kishikawa Y, Kawahara Y, Yamada M, Kaneko F, Kawahara H, Nishi A. The spontaneously hypertensive rat/lzm (SHR/Izm) shows attention deficit/ hyperactivity disorder-like behaviors but without impulsive behavior: therapeutic implications of low-dose methylphenidate. Behav Brain Res. 2014;274:235-42

42. Pandolfo P, Machado NJ, Kofalvi A, Takahashi RN, Cunha RA. Caffeine regulates frontocorticostriatal dopamine transporter density and improves attention and cognitive deficits in an animal model of attention deficit hyperactivity disorder. Eur Neuropsychopharmacol. 2013;23(4):317-28.

43. Jones SR, Gainetdinov RR, Jaber M, Giros B, Wightman RM, Caron MG. Profound neuronal plasticity in response to inactivation of the dopamine transporter. Proc Natl Acad Sci U S A. 1998:95(7):4029-34.

44. Granas C, Ferrer J, Loland CJ, Javitch JA, Gether U. N-terminal truncation of the dopamine transporter abolishes phorbol ester- and substance $P$ receptor-stimulated phosphorylation without impairing transporter internalization. J Biol Chem. 2003:278(7):4990-5000.

45. Kravitz AV, Kreitzer AC. Striatal mechanisms underlying movement, reinforcement, and punishment. Physiology (Bethesda). 2012;27(3):167-77.

46. DeLong MR. Primate models of movement disorders of basal ganglia origin. Trends Neurosci. 1990;13(7):281-5.

47. Kravitz AV, Freeze BS, Parker PR, Kay K, Thwin MT, Deisseroth K, et al. Regulation of parkinsonian motor behaviours by optogenetic control of basal ganglia circuitry. Nature. 2010;466(7306):622-6.
48. Giros B, Jaber M, Jones SR, Wightman RM, Caron MG. Hyperlocomotion and indifference to cocaine and amphetamine in mice lacking the dopamine transporter. Nature. 1996;379(6566):606-12.

49. Muneoka K, Kuwagata M, Iwata M, Shirayama Y, Ogawa T, Takigawa M. Dopamine transporter density and behavioral response to methylphenidate in a hyperlocomotor rat model. Congenit Anom (Kyoto). 2006;46(3):155-9.

50. Hamida SB, Plute E, Cosquer B, Kelche C, Jones BC, Cassel JC. Interactions between ethanol and cocaine, amphetamine, or MDMA in the rat: thermoregulatory and locomotor effects. Psychopharmacology. 2008; 197(1):67-82.

51. Steinau S. Diagnostic criteria in attention deficit hyperactivity disorder changes in DSM 5. Front Psychiatry. 2013;4:49.

52. Dovis S, Van der Oord S, Wiers RW, Prins PJ. What part of working memory is not working in ADHD? Short-term memory, the central executive and effects of reinforcement. J Abnorm Child Psychol. 2013; 41(6):901-17.

53. Tillman C, Eninger L, Forssman L, Bohlin G. The relation between working memory components and ADHD symptoms from a developmental perspective. Dev Neuropsychol. 2011;36(2):181-98.

54. Cardinal RN, Winstanley CA, Robbins TW, Everitt BJ. Limbic corticostriatal systems and delayed reinforcement. Ann N Y Acad Sci. 2004;1021:33-50

55. Sullivan RM, Brake WG. What the rodent prefrontal cortex can teach us about attention-deficit/hyperactivity disorder: the critical role of early developmental events on prefrontal function. Behav Brain Res. 2003; 146(1-2):43-55.

56. Findling RL. Evolution of the treatment of attention-deficit/hyperactivity disorder in children: a review. Clin Ther. 2008;30(5):942-57.

57. Swanson J, Baler RD, Volkow ND. Understanding the effects of stimulant medications on cognition in individuals with attention-deficit hyperactivity disorder: a decade of progress. Neuropsychopharmacology. 2011;36(1):207-26

58. Wigal SB. Efficacy and safety limitations of attention-deficit hyperactivity disorder pharmacotherapy in children and adults. CNS Drugs. 2009;23(Suppl 1):21-31.

59. Dougherty DD, Bonab AA, Spencer TJ, Rauch SL, Madras BK, Fischman AJ. Dopamine transporter density in patients with attention deficit hyperactivity disorder. Lancet. 1999;354(9196):2132-3.

60. Krause KH, Dresel SH, Krause J, Kung HF, Tatsch K. Increased striatal dopamine transporter in adult patients with attention deficit hyperactivity disorder: effects of methylphenidate as measured by single photon emission computed tomography. Neurosci Lett. 2000;285(2):107-10.

61. Cao AH, Yu L, Wang YW, Wang JM, Yang LJ, Lei GF. Effects of methylphenidate on attentional set-shifting in a genetic model of attention-deficit/hyperactivity disorder. Behav Brain Funct. 2012;8(1):10.

62. Watanabe $Y$, Fujita M, Ito $Y$, Okada T, Kusuoka H, Nishimura T. Brain dopamine transporter in spontaneously hypertensive rats. J Nucl Med. 1997;38(3):470-4.

63. Umehara M, Ago Y, Kawanai T, Fujita K, Hiramatsu N, Takuma K, et al. Methylphenidate and venlafaxine attenuate locomotion in spontaneously hypertensive rats, an animal model of attention-deficit/hyperactivity disorder, through alpha2-adrenoceptor activation. Behav Pharmacol. 2013; 24(4):328-31.

64. Yang PB, Swann AC, Dafny N. Dose-response characteristics of methylphenidate on locomotor behavior and on sensory evoked potentials recorded from the VTA, NAC, and PFC in freely behaving rats. Behav Brain Funct. 2006:2:3.

65. Xu H, Yang HJ, Rose GM. Chronic haloperidol-induced spatial memory deficits accompany the upregulation of $D(1)$ and $D(2)$ receptors in the caudate putamen of C57BL/6 mouse. Life Sci. 2012;91(9-10):322-8.

66. Ueno K, Togashi H, Matsumoto M, Ohashi S, Saito H, Yoshioka M. Alpha4beta2 nicotinic acetylcholine receptor activation ameliorates impairment of spontaneous alternation behavior in stroke-prone spontaneously hypertensive rats, an animal model of attention deficit hyperactivity disorder. J Pharmacol Exp Ther. 2002;302(1):95-100.

67. Foster JD, Pananusorn B, Vaughan RA. Dopamine transporters are phosphorylated on N-terminal serines in rat striatum. J Biol Chem. 2002; 277(28):25178-86.

68. Cole CJ, Mercaldo V, Restivo L, Yiu AP, Sekeres MJ, Han JH, et al. MEF2 negatively regulates learning-induced structural plasticity and memory formation. Nat Neurosci. 2012;15(9):1255-64. 
69. Joels $\mathrm{G}$, Lamprecht R. Interaction between N-ethylmaleimide-sensitive factor and GluR2 is essential for fear memory formation in lateral amygdala. J Neurosci. 2010;30(47):15981-6.

70. Tu J, Zhang X, Zhu Y, Dai Y, Li N, Yang F, et al. Cell-permeable peptide targeting the Nrf2-Keap1 interaction: a potential novel therapy for global cerebral ischemia. J Neurosci. 2015;35(44):14727-39.

71. Li S, Li Z, Pei L, Le AD, Liu F. The alpha7nACh-NMDA receptor complex is involved in cue-induced reinstatement of nicotine seeking. J Exp Med. 2012; 209(12):2141-7.

72. Lee FH, Su P, Xie YF, Wang KE, Wan Q, Liu F. Disrupting GluA2-GAPDH interaction affects axon and dendrite development. Sci Rep. 2016;6; 30458.

73. Brown V, Liu F. Intranasal delivery of a peptide with antidepressant-like effect. Neuropsychopharmacology. 2014;39(9):2131-41.

Ready to submit your research? Choose BMC and benefit from:

- fast, convenient online submission

- thorough peer review by experienced researchers in your field

- rapid publication on acceptance

- support for research data, including large and complex data types

- gold Open Access which fosters wider collaboration and increased citations

- maximum visibility for your research: over $100 \mathrm{M}$ website views per year

At $\mathrm{BMC}$, research is always in progress.

Learn more biomedcentral.com/submissions 